\title{
PEMBERDAYAAN MASYARAKAT DESA LIMBANG JAYA 1 KECAMATAN TANJUNG BATU, KABUPATEN OGAN ILIR DALAM PROGRAM PEMBERDAYAAN DESA
}

\author{
Oleh: Rina Ratih dan \\ 7 Mahasiswa KKN Muhammadiyah Untuk Negeri Periode IV Tahun 2016 \\ Universitas Ahmad Dahlan Yogyakarta \\ E-mail: abdulmuthaliba197@gmail.com
}

\begin{abstract}
Ringkasan
Salah satu permasalahan yang ada di masyarakat Desa Limbang Jaya 1, Kecamatan Tanjung Batu, Kabupaten Ogan Ilir, Sumatra Selatan adalah banyaknya sampah di setiap jalan atau di depan rumah yang membuat berserakan dimana-mana. Maka program KKN Muhammadiyah Untuk Negeri difokuskan pada Pemberdayaan Desa. Program ini bertujuan memberdayakan masyarakat Desa Limbang jaya 1 dalam program Peduli Lingkungan. Metode pelaksanaan program KKN MU meliputi: Pembuatan nama-nama jalan, Pembuatan Gapura, pemberdayaan Ibu-ibu PKK dan pemberdayaan lingkungan. Dampak dari kegiatan KKN MU ini adalah : 1) Setiap nama jalan di Desa limbang Jaya 1 sudah ada plang nama-nama jalan sehingga memudahkan untuk mencari alamat yang ingin dituju, 2) Dengan adanya gapura ucapan selamat datang, memberikan kesan atau ucapan selamat datang di desa, 3), Dengan melimpahnya Sumber daya Manusia yang dimiliki Desa Limbang jaya 1, makanya mahiswa memberikan pembekalan kepada Ibu-ibu PKK tentang pendidikan kreativitas, 4) Tujuannya agar lingkungan Desa bersih, sehat dan tidak ada lagi yang namanya sampah berserakan dimana-mana.
\end{abstract}

Kata kunci : Pemberdayaan,Desa, Peduli Lingkungan.

\begin{abstract}
One of the problems that existed in Limbang Jaya 1 community, Tanjung Batu Subdistrict, Ogan Ilir Regency, South Sumatra is the amount of garbage in every street or in front of the house which makes it scattered everywhere. So the program of KKN Muhammadiyah for Negeri focused on Village Empowerment. This program aims to empower the people of Desa Limbang jaya 1 in the Environmental Care program. Methods of implementation of KKN MU program include: Making street names, Making Gapura, empowering PKK mothers and environmental empowerment. The impact of this KKN MU activities are: 1) Every street name in Desa limbang Jaya 1 already have plang names of roads making it easier to find the address you want to go, 2) With a welcome greeting gate, give the impression or welcome greeting at 3) With the abundance of Human Resources owned by Desa Limbang jaya 1, so the students provide debriefing to the PKK Mothers about creativity education, 4) The goal for the village environment clean, healthy and no more garbage scattered everywhere
\end{abstract}

Keywords: Empowerment, Village, Environmental Care.

\section{A. PENDAHULUAN}

Kuliah Kerja Nyata (selanjutnya disingkat KKN) adalah suatu bentuk pendidikan dengan cara memberikan pengalaman belajar kepada mahasiswa untuk hidup ditengahtengah masyarakat di luar kampus dan secara langsung mengidentifikasi serta menangani masalah-masalah pembangunan yang dihadapi. KKN dilaksanakan oleh perguruan tinggi dalam upaya meningkatkan isi dan bobot pendidikan bagi mahasiswa dan untuk mendapatkan nilai tambah yang lebih besar pada perguruan tinggi. 
Kegiatan KKN dilaksanakan di luar kampus dengan maksud meningkatkan relevansi pendidikan tinggi dengan perkembangan dan kebutuhan masyarakat akan ilmu pengetahuan, informasi, teknologi, budaya, keagamaan serta seni untuk melaksanakan pembangunan yang semakin meningkat, serta meningkatkan presepsi mahasiswa tentang relevansi antar kurikulum yang dipelajari di kampus dengan realita pembangunan dalam masyarakat.

Bagi mahasiswa, kegiatan KKN haruslah dilaksanakan sebagai pemahaman belajar yang baru dan tidak akan peroleh di dalam kampus. KKN harus menekankan aspek pengalaman belajar yang menghubungkan konsep- konsep akademis dengan realitas kehidupan masyarakat. Program KKN ini merefleksikan pengetahuan teoritik yang disinergikan dengan pengalaman di lapangan serta diharapkan mampu meningkatkan kepribadian mahasiswa dan menumbuhkan rasa percaya diri dalam kehidupan sosial kemasyarakatan.

\section{B. METODE PELAKSANAAN}

Untuk mencapai tujuan yang diharapkan, program KKN MU Untuk Negeri di Desa Limbang Jaya 1 dilakukan dengan Pemberdayaan masyarakat melalui Pembuatan Nama-nama Gapura, Pemberdayaan Ibu-ibu PKK dan Pemberdayaan lingkungan. Ringkasan metode pelaksanaan beserta jam kerja efektif mahasiswa (JKEM) tersaji pada table I.

Tabel I. Metode, Kegiatan, JKEM dan keterlibatan mahasiswa

\begin{tabular}{|c|l|l|c|c|}
\hline No & \multicolumn{1}{|c|}{ Metode } & \multicolumn{1}{|c|}{ Kegiatan } & JKEM & $\begin{array}{l}\text { Jumlah } \\
\text { mahasiswa } \\
\text { yang terlibat }\end{array}$ \\
\hline 1. & Pembuatan Nama-nama Jalan & $\begin{array}{l}\text { Pemberdayaan } \\
\text { Desa }\end{array}$ & $1 \times 12$ Jam & 5 Mahasiswa \\
\hline 2. & $\begin{array}{l}\text { Pembuatan Gapura/Ucapan } \\
\text { Selamat Datang }\end{array}$ & $\begin{array}{l}\text { Pemberdayaan } \\
\text { Desa }\end{array}$ & $1 \times 12$ Jam & 5 Mahasiswa \\
\hline 3. & Pemberdayaan Ibu-ibu PKK & $\begin{array}{l}\text { Pemberdayaan } \\
\text { Desa }\end{array}$ & $1 \times 3$ Jam & 5 Mahasiswa \\
\hline 4. & Pemberdayaan lingkungan & $\begin{array}{l}\text { Pemberdayaan } \\
\text { Desa }\end{array}$ & $1 \times 12$ jam & 10 Mahasiswa \\
\hline
\end{tabular}

\section{HASIL, PEMBAHASAN DAN DAMPAK}

\section{Hasil dan Pembahasan}

Kabupaten Ogan Ilir adalah salah satu kabupaten di Provinsi Sumatera Selatan. Ogan Ilir berada di jalur lintas timur Sumatera dan pusat pemerintahannya terletak sekitar $35 \mathrm{~km}$ dari Kota Palembang. Kabupaten ini merupakan pemekaran dari Kabupaten Ogan Komering Ilir. Pada awalnya Kabupaten Ogan Ilir terdiri dari 6 kecamatan. Namun dalam perkembangannya berkembang menjadi 16 kecamatan. Secara geografis Kabupaten Ogan Ilir terletak diantara $3^{\circ} 02^{\prime}$ sampai $3^{\circ} 48^{\prime}$ Lintang Selatan dan di antara $104^{\circ} 20^{\prime}$ sampai $104^{\circ} 48^{\prime}$ Bujur Timur. 
Diterbitkan oleh Lembaga Pengabdian kepada Masyarakat

Universitas Ahmad Dahlan Yogyakarta

Di Kabupaten Ogan Ilir terdapat 16 kecamatan yaitu Kecamatan Indralaya Selatan, Kecamatan Utara, Kecamatan Indralaya, Kecamatan Kandis, Kecamatan Lubuk Keliat, Kecamatan Muara Kuang, Kecamatan Payaraman, Kecamatan Pemulutan Barat, Kecamatan Pemulutan Selatan, Kecamatan Pemulutan, Kecamatan Rambang Kuang, Kecamatan Rantau Alai, Kecamatan Rantau Panjang, Kecamatan Sungai Pinang, Kecamatan Tanjung Batu, dan Kecamatan Tanjung Raja.

Dari pembahasan diatas, berikut ini tentang diskripsi wilayah.

a. Profil Desa

Desa Limbang Jaya I terletak di Kecamatan Tanjung Batu Kabupaten Ogan Ilir. Adapun kecamatan Tanjung Batu memiliki 18 Desa Yaitu Desa Limbang Jaya I, Desa Limbang Jaya 2, Desa Tanjung Pinang 1, Desa Tanjung Pinang 2, Fajar Bulan, Bangun Jaya, Tanjung Atap, Sri Tanjung, Sri Bandung, Tanjung Batu, Tanjung Batu Seberang, Tanjung Atap Barat, Tanjung Laut, Tanjung Batu Ketai, Senuro, Tanjung Batu Timur, Tanjung Atap, dan Tanjung Atap Timur.

Secara geografis, desa Limbang Jaya 1 memiliki luas 3000 M2 dan terletak di antara Tanjung Laut, Burai, Siring Alam, dengan luas wilayah bangunan $8 \mathrm{Ha}$, luas pertanian $685 \mathrm{Ha}$, dan luas lahan lebak $49 \mathrm{Ha}$.

Peran serta masyarakat dalam pengelolaan lingkungan, pembuatan namanama jalan dan sebagainya merupakan kesediaan masyarakat untuk membantu berhasilnya program pengembangan pengelolaan lingkungan sesuai dengan kemampuan setiap orang tanpa mengorbankan kepentingan diri sendiri. Tanpa adanya peran serta masyarakat semua program pengelolaan persampahan, pembuatan nama-nama jalan dan sebagainya yang direncanakan akan sia-sia. Salah satu pendekatan masyarakat untuk dapat membantu program pemerintah dalam keberhasilan adalah membiasakan masyarakat pada tingkah laku yang sesuai dengan program persampahan yaitu merubah persepsi masyarakat terhadap pengelolaan sampah yang tertib, lancar dan merata, merubah kebiasaan masyarakat dalam pengelolaan sampah yang kurang baik dan faktor-faktor sosial, struktur dan budaya setempat (Wibowo dan Djajawinata, 2004). Menurut Syafrudin (2004), salah satu alternatif yang bisa dilakukan adalah melaksanakan program pengelolaan sampah berbasis masyarakat, seperti minimalisasi limbah dan melaksanakan 5 R (Reuse, Recycling, Recovery, Replacing dan Refilling).

Berdasarkan permasalahan tersebut, maka ditetapkan tujuan program KKN MU Negeri adalah pemberdayaan masyarakat Desa Limbang Jaya 1 dalam kepedulian lingkungan.

b. Luas Wilayah

\begin{tabular}{|l|l|}
\hline Uraian & Luas \\
\hline Luas Wilayah & $693 \mathrm{Ha}$ \\
\hline Luas Wilayah Bangunan & $8 \mathrm{Ha}$ \\
\hline Luas Wilayah Pertanian & $685 \mathrm{Ha}$ \\
\hline a. Lahan Kering & $629 \mathrm{Ha}$ \\
\hline$-\quad$ Pekarangan & $16,5 \mathrm{Ha}$ \\
\hline$-\quad$ Tegal Huma & $601 \mathrm{Ha}$ \\
\hline
\end{tabular}




\begin{tabular}{|c|c|c|}
\hline & Lahan Kritis & \\
\hline & Hutan/Padang Alang-alang & $26 \mathrm{Ha}$ \\
\hline b. & han Rawa-rawa & $7 \mathrm{Ha}$ \\
\hline $\mathrm{c}$. & han Lebak & $49 \mathrm{Ha}$ \\
\hline & Lebak Pematang & $32 \mathrm{Ha}$ \\
\hline & Lebak Tengahan & $17 \mathrm{Ha}$ \\
\hline & Lebak Dalam & \\
\hline
\end{tabular}


Diterbitkan oleh Lembaga Pengabdian kepada Masyarakat

Universitas Ahmad Dahlan Yogyakarta

c. Denah Peta Limbang Jaya 1
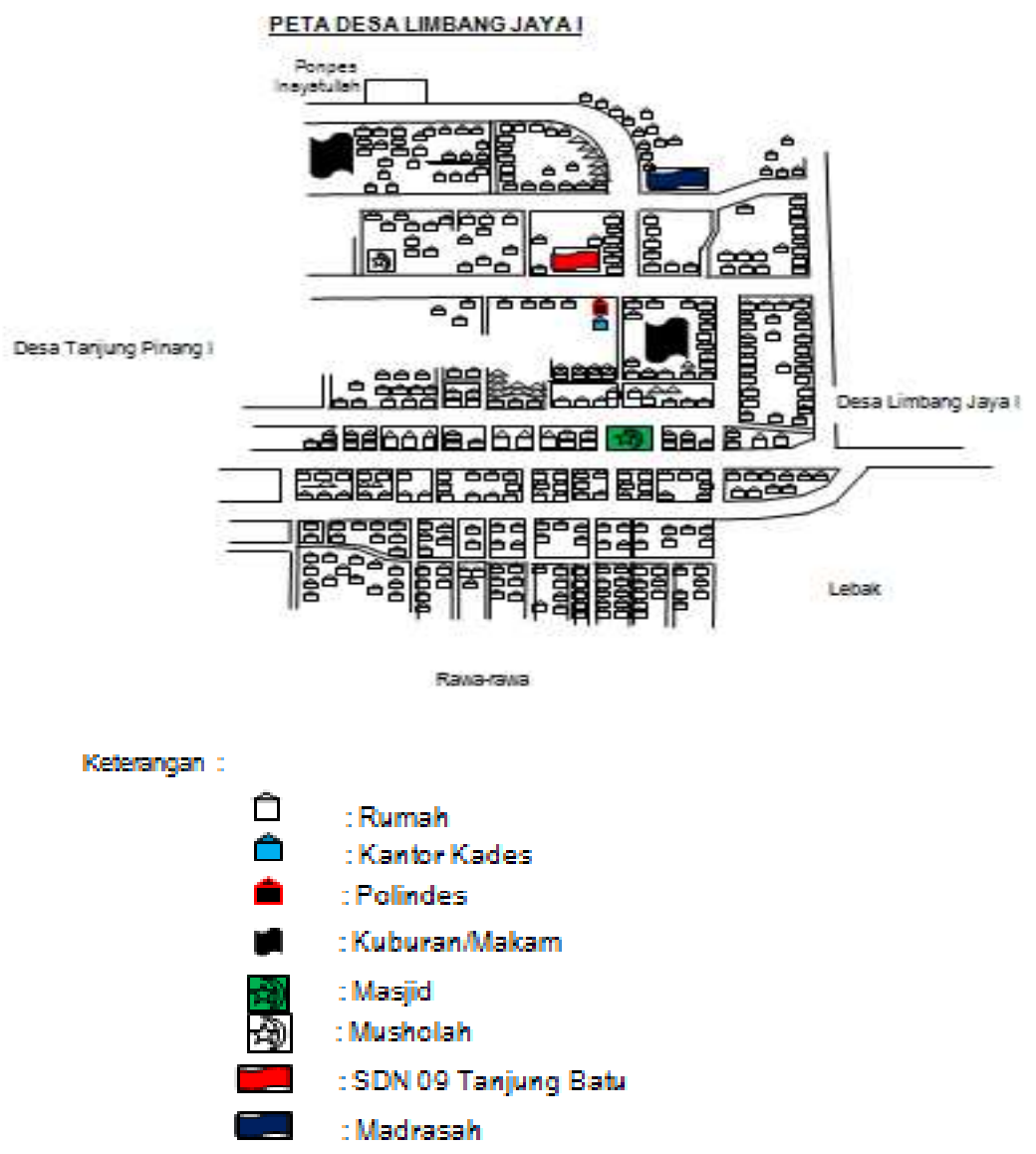

d. Penduduk

Sumber Daya Manusia, Komposisi Penduduk Bedasarkan Agama Semua penduduk atau masyarakat di Desa Limbang Jaya I Kecamatan Tanjung Batu Kabupaten Ogan Ilir menganut Agama Islam. Komposisi Penduduk Bedasarkan Jenis Kelamin Komposisi penduduk di Desa Limbang Jaya I Kecamatan Tanjung Batu Kabupaten Ogan Ilir berdasarkan jenis kelamin antara lain:

- Laki-laki : 831 jiwa

- Perempuan : 871 jiwa

- Total : 1.702 jiwa

- Jumlah KK : $428 \mathrm{KK}$

Komposisi Penduduk Berdasarkan Tahapan Keluarga Sejahtera Komposisi penduduk berdasarkan tahapan keluarga sejahtera di Desa Limbang Jaya I Kecamatan Tanjung Batu Kabupaten Ogan Ilir antara lain 


\begin{tabular}{|l|l|l|}
\hline No & Uraian & Jumlah \\
\hline 1 & Keluarga Prasejahtera (miskin) & $119 \mathrm{KK}$ \\
\hline 2 & Keluarga Sejahtera I & $97 \mathrm{KK}$ \\
\hline 3 & Keluarga Sejahtera II & $87 \mathrm{KK}$ \\
\hline 4 & Keluarga Sejahtera III & $32 \mathrm{KK}$ \\
\hline 5 & Keluarga Kaya & $21 \mathrm{KK}$ \\
\hline
\end{tabular}

e. Pekerjaan

Adapun data tentang pekerjaan warga di Desa Limbang Jaya I Kecamatan Tanjung Batu Kabupaten Ogan Ilir adalah sebagi berikut:

\begin{tabular}{|l|l|l|}
\hline No & Jenis Pekerjaan & Jumlah (Orang) \\
\hline 1 & $\begin{array}{l}\text { PNS/ TNI/POLRI, Para Medis, Pensiunan, } \\
\text { Pum }\end{array}$ & $15 \mathrm{KK}$ \\
\hline 2 & Kerajinan & $235 \mathrm{KK}$ \\
\hline 3 & Dagang & $43 \mathrm{KK}$ \\
\hline 4 & Perikanan & - \\
\hline 5 & Buruh \& Sopir & $50 \mathrm{KK}$ \\
\hline 6 & Peternak & $7 \mathrm{KK}$ \\
\hline 7 & Petani & $28 \mathrm{KK}$ \\
\hline JUMLAH & $428 \mathrm{KK}$ \\
\hline
\end{tabular}

f. Pendidikan

Adapun tingkat pendidikan di Desa Limbang Jaya I Kecamatan Tanjung Batu Kabupaten Ogan Ilir, sebagai berikut:

\begin{tabular}{|l|l|l|}
\hline No & Tingkat Pendidikan & Jumlah \\
\hline 1 & Tidak Sekolah & 1.114 jiwa \\
\hline 2 & SD Sederajat & 203 jiwa \\
\hline 3 & SMP Sederajat & 198 jiwa \\
\hline 4 & SMA Sederajat & 159 jiwa \\
\hline 5 & Diploma & \\
\hline 6 & Sarjana & 50 jiwa \\
\hline 7 & Pascasarjana & 30 jiwa \\
\hline JUMLAH & \\
\hline
\end{tabular}

2. Dampak yang Ditimbulkan Dari KKN MU Untuk negeri adalah sebagi berikut:

a. Mendidik masyarakat untuk tidak membuang sampah sembarangan.

b. Membantu desa dalam mempromosikan tempat-tempat wisata yang dimiliki oleh desa limbang jaya 1 ke masyarakat luas. 
Diterbitkan oleh Lembaga Pengabdian kepada Masyarakat

Universitas Ahmad Dahlan Yogyakarta

c. Memanfaatkan limbah sampah untuk dijadikan kerajianan tangan seperti membuat tempat tisu dari Koran bekas dan kerajian tangan lainnya yang bernilai ekonomi.

d. Dengan adanya pelatihan, diharapakn masyarakat dapat membantu prekonomian keluarga yang dihasilkan dari kerajinan tangan.

\section{Gambaran Pelaksanaan:}

Gambar aktivitas Mahasiswa KKN MU Untuk Negeri dan masyarakat Desa Limbang Jaya 1 dalam program pemberdayaan Masrakat tersaji pada gambar 4.
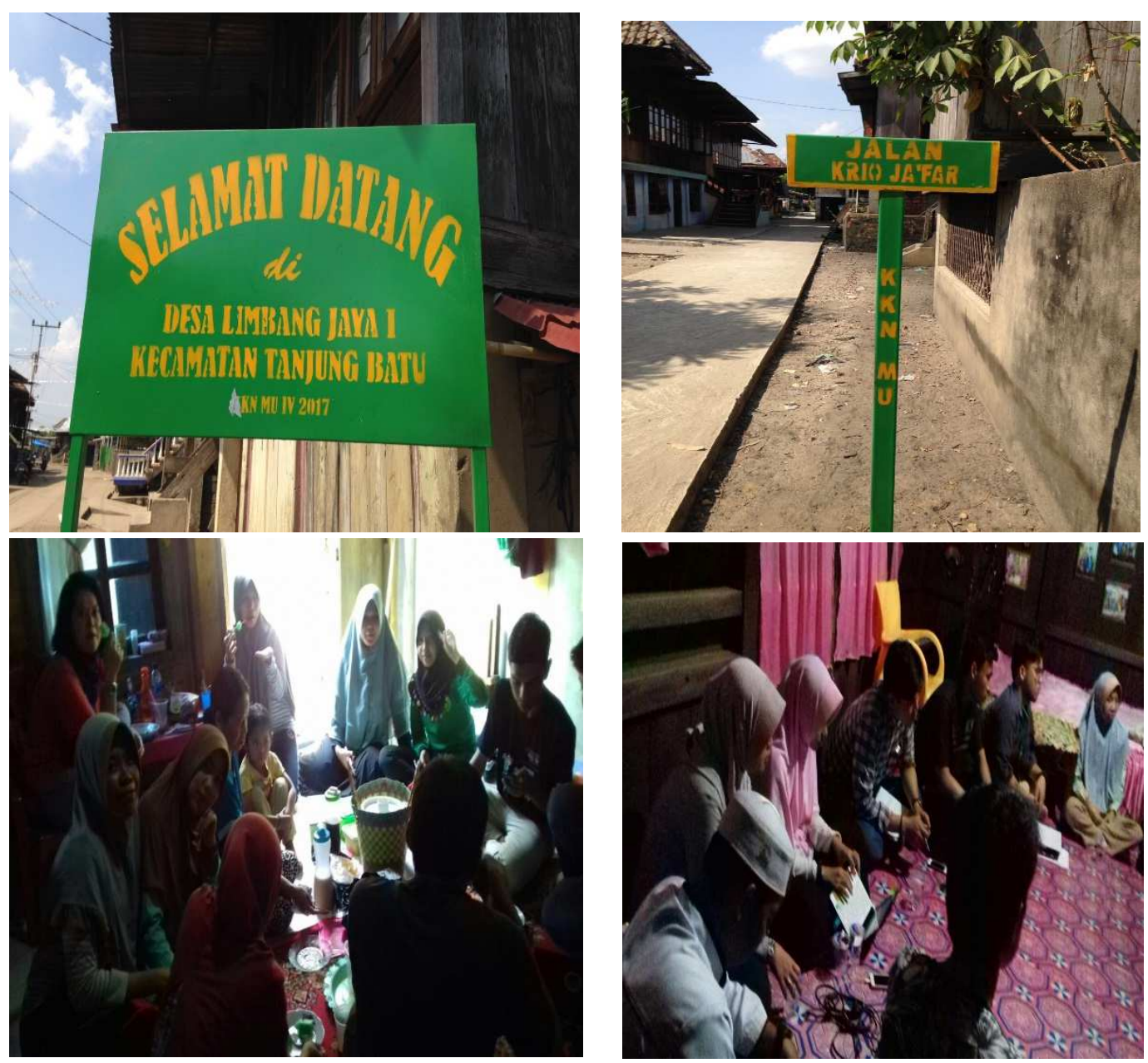

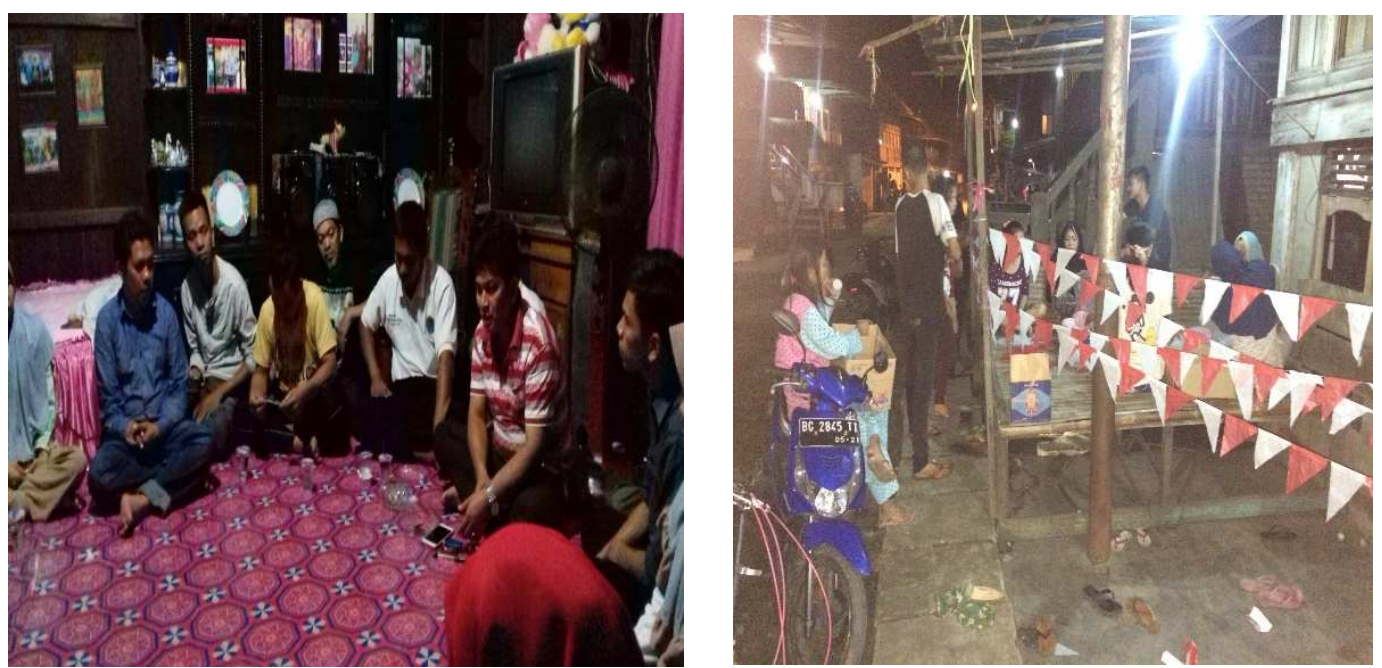

Gambar 4. Aktivitas mahasiswa KKN MU Untuk Negeri dan masyarakatDesa Limbang Jaya 1 dalam program pemberdayaan Masyarakat.

Dari gambar 4 terlihat program KKN MU Untuk Negeri di Desas Limbang Jaya $1<$ Kecamatan Tanjung Batu dapat terlaksana dengan partisipasi masyarakat yang cukup tinggi dengan kata lain dapat memperdayakan masyarakat dalam program-program yang telah direncanakan. Dampak dari kegiatan KKN MU Untuk Negeri ini adalah: 1) Setiap Nama-nama jalan yang ada di Desa limbang Jaya 1 sudah ada plang/nama-nama jalannya. Sehingga mudah untuk mencari alamat yang ingin dituju, 2) Dengan adanya Gapura/ucapan selamat datang, memberikan kesan tersendiri yang dimana sebelunya tidak memiliki ucapan selamat datang dan sekarng sudah memiliki, 3), Dengan melimpahnya Sumber daya Manusia yang dimiliki Desa Limbang jaya 1, makanya mahiswa bergerak dan memberikan pembekalan kepada Ibu-ibu PKK tentang kreativitas yang ada pada diri kita, 4) Tujuannya agar lingkungan Desa bersih, sehat dan tidak ada lagi yang namanya sampah berserakan dimana-mana.

\section{KESIMPULAN}

Program KKN UAD MU Untuk Negeri dalam Pemberdayakan Desa Kecamatan Tanjung Batu terhadap kepedulian lingkungan telah berjalan dengan baik sesuai dengan yang diharapksan.

\section{DAFTAR PUSTAKA}

Syafrudin, 2004, Pengelolaan Sampah Berbasis Masyarakat.Prosiding, Diskusi Interaktif Pengelolaan Sampah Terpadu, Program Magister Ilmu Lingkungan Universitas Diponegoro, Semarang.

Wibowo A dan Djajawinata D.T, 2004. Penanganan Sampah Perkotaan Terpadu.Diakses tanggal 4 Desember 2016 pada halaman

www.kkpi.go.id 